\title{
Toxicity Evaluation of Chlorpyrifos Metabolite 3,5,6- trichloro-2-pyridinol to Eisenia Fetida in Different Soils
}

\section{Kaixuan Hou}

Shandong Agricultural University

\section{Yue Yang}

Shandong Agricultural University

Lei Zhu

Shandong Agricultural University

\section{Ruolin Wu}

Shandong Agricultural University

\section{Zhongkun Du}

Shandong Agricultural University

\section{Bing Li}

Shandong Agricultural University

\section{Lusheng Zhu ( $\square$ lushzhu@sdau.edu.cn )}

Shandong Agricultural University https://orcid.org/0000-0001-6212-1965

\section{Shujuan Sun}

Shandong Agricultural University

\section{Research Article}

Keywords: Earthworms, OECD Artificial soil, Fluvo-aquic soil, Black soil, Red clay, Oxidative stress, Integrated Biomarker Response (IBR)

Posted Date: January 3rd, 2022

DOI: https://doi.org/10.21203/rs.3.rs-529333/v2

License: (c) (i) This work is licensed under a Creative Commons Attribution 4.0 International License. Read Full License 


\section{Abstract}

The present study utilized a biomarker response method to evaluate the effect of 3,5,6-trichloro-2pyridinol (TCP) in artificial and natural soils on Eisenia fetida after 7, 14, 28, 42 and 56 days exposure. Results indicated that TCP induced excessive reactive oxygen species, caused oxidative stress and DNA damage to Eisenia fetida. Biomarker responses were standardized to calculate the Integrated Biomarker Response (IBR) index. The IBR index of three enzymes activities showed that TCP induced the enzymes activities of earthworm in red clay was stronger than the other three soils. Specifically, chlorpyrifos exposure group showed a lower toxicity than TCP exposure group after 28 days exposure but a higher toxicity than TCP exposure group after 56 days exposure. Despite the deficiencies of this study, the above information is of great significance for assessing the risk of chlorpyrifos and its metabolite TCP pollution in soil ecosystems.

\section{Introduction}

The extensive use of pesticides has brought great dividends to agricultural production, but also inevitably caused harm to non-target organisms. Chlorpyrifos, an organophosphate insecticide (Jhon and Shaike. 2015), has been widely used during the past half century for pest control. However, chlorpyrifos is highly toxic to non-target organisms including avian species $\left(E_{50} 39.2 \mathrm{mg} / \mathrm{kg}\right)$ and rodents $\left(\mathrm{EC}_{50} 66 \mathrm{mg} / \mathrm{kg}\right)$. Chlorpyrifos is toxic to soil microorganisms (Dutta et al., 2010; Orts et al., 2017), plants (Bassey et al., 2015), aquatic system (Ali et al., 2009; Costa et al., 2015; Bonifacio et al., 2017) and even to the higher vertebrates (Sandal and Yilmaz, 2011; Wang et al., 2012; Ojha et al., 2013). Recently, Tiwari et al. (2019) highlighted that chlorpyrifos could alter the activity of acetylcholinesterase (AChE), oxidative stress related enzymes, lipid peroxidation (LPO), glutathione content and glutathione S-transferase (GST) activity in Eudrilus eugeniae. Similarly, García-Gómez et al. (2019) using earthworms (Eisenia andrei) demonstrated that chlorpyrifos exposure $(40 \mathrm{mg} / \mathrm{kg})$ reduced AChE activity and impacted male reproductive abilities. Our previous study (Zhu et al., 2020) using a biomarkers response method demonstrated that chlorpyrifos caused oxidative and DNA damage to Eisenia fetida although the toxicological response varied depending on physicochemical properties of soil. As such, previous studies have detailed the behavioral, neurological and reproductive effects of chlorpyrifos on organisms thus providing a good knowledge base regarding chlorpyrifos' environmental impact.

However, once chlorpyrifos has entered the soil environment, it may be subject to transformation via biotic and abiotic processes. Therefore, the toxicity of metabolites should also be considered when assessing ecological impact. 3,5,6-trichloro-2-pyridinol (TCP) is the primary metabolite of chlorpyrifos (Žabar et al., 2016; Wang et al., 2019). TCP has a half-life in soil of up to 360 days and an aqueous solubility of $80.9 \mathrm{mg} / \mathrm{L}$, indicating its longer persistence in the environment and potential mobility (Deng et al., 2016). Research on TCP has focused on degradation or biodegradation (Bempelou et al., 2018; Yu et al., 2019; Zhang et al., 2019) as well as aquatic toxicity (Wang et al., 2014; Suvarchala and Philip, 2016; Echeverri-Jaramillo et al., 2020) and toxicity to higher organisms (e.g. mice) (Deng et al., 2016). However, to our best knowledge, there is a lack of published literature on the effect of TCP on earthworms. This is 
significant given the role of earthworms in contributing to soil structure and improvement (Blakemore and Hochkirch, 2017).

In this study, the effects of TCP exposure on Eisenia fetida were assessed by monitoring the response of biomarkers including reactive oxygen species (ROS), enzyme activities of superoxide dismutase (SOD), catalase (CAT), as well as GST, LPO (MDA content), and 8-hydroxydeoxyguanosine (8-OHdG) following exposure to TCP. Artificial soil and three different natural soils were selected to assess soil type effects on TCP toxicological response. The Integrated Biomarker Response (IBR) index (Samanta et al., 2018;

Sanchez-Hernandez et al., 2019) was calculated to compare the effect of TCP exposure to earthworms in different soils and to compare exposure effect magnitude with chlorpyrifos, the parent compound.

It was hypothesized that TCP would exhibit a greater adverse response in earthworms compared to the parent compound chlorpyrifos because of its longer environmental persistence and mobility.

\section{Materials And Methods}

\subsection{Chemical and reagents}

TCP (CAS 6515-38-4; 99.0\% purity) was purchased from AccuStandard Co., Ltd. (New Haven, USA). The ELISA kit used to assess 8-OHdG content was purchased from Hengyuan Biological Technology Co. Ltd. (Shanghai, China). Chromatographical grade acetonitrile was purchased from Tedia Co., Inc. (Ohio, USA). Other reagents involved in this study were all of analytical purity.

\subsection{Soil, earthworms and experiment design}

Soils used in this study were OECD artificial soil, fluvo-aquic soil, black soil and red clay. According to the Organization for Economic Co-operation and Development guideline (OECD 222, 2016), artificial soil consists of 10 per cent sphagnum peat, 20 per cent kaolin clay, 70 per cent air-dried quartz sand and a small amount of calcium carbonate for $\mathrm{pH}$ regulation (Zhang et al., 2018; Liu et al., 2020a). The fluvoaquic soil was sampled from Dezhou, Shandong, China $\left(36.78^{\circ} \mathrm{N}, 116.54^{\circ} \mathrm{E}\right)$, the black soil from Changchun, Jilin, China $\left(43.80^{\circ} \mathrm{N}, 125.40^{\circ} \mathrm{E}\right)$ and the red clay from Nanning, Guangxi, China $\left(22.74^{\circ} \mathrm{N}\right.$, $109.31^{\circ} \mathrm{E}$ ), respectively. Properties of the three soils are shown in Table S1.

Adult Eisenia fetida were acquired from an earthworm farm (Shandong, China). Healthy, mature earthworms weighing 300 to $500 \mathrm{mg}$ and possessing a visible clitellum were randomly selected for TCP exposure studies (OECD 222, 2016).

Chlorpyrifos residues in soil from of cotton/wheat fields have been reported to range from 0.18 to 1.99 $\mathrm{mg} / \mathrm{kg}$ (Rafique et al., 2016). In our previous study on the effect of chlorpyrifos on earthworms, concentrations utilized ranged from 0.01 to $1 \mathrm{mg} / \mathrm{kg}$ (Zhu et, al. 2020). As TCP is the main degradation product of chlorpyrifos (Echeverri-Jaramillo et al., 2020) with residual soil concentrations lower than that of chlorpyrifos, TCP concentrations used in this study were $0.01,0.1$, and $0.5 \mathrm{mg} / \mathrm{kg}$. A solvent control group $(0 \mathrm{mg} / \mathrm{kg})$ was included where only acetonitrile was added to the soil. A small amount of dry soil 
(about $10 \mathrm{~g}$ ) was mixed with $1 \mathrm{~mL}$ of TCP-acetonitrile solution $(5,50$ and $500 \mathrm{mg} / \mathrm{L})$ in a stainless-steel basin. This soil was then mixed with the remaining soil $(490 \mathrm{~g})$ to allow acetonitrile to volatilized (in a fume hood) prior to adjusting soil moisture to $60 \%$ water holding capacity. Soil was transferred to $1 \mathrm{~L}$ glass beakers with three replicates prepared for each concentration and soil type $(3 \times 500 \mathrm{~g})$. Twenty earthworms were randomly selected and placed on the soil surface. Plastic wrap, perforated with a toothpick, was used to cover the beakers. Assays were conducted at $20^{\circ} \mathrm{C}, 80 \%$ humidity and a light-dark cycle of 16 hours light and 8 hours dark with illumination of 650 lux according to OECD 222, 2016.

\subsection{Sample preparation and biomarkers responses assessment}

On day 7, 14, 21, 28 and 56, 3 earthworms were sampled to assess biomarker responses. One was used for the determination of ROS, one for the determination of SOD, CAT, GST and MDA, and one for the determination of 8-OHdG. To assess ROS, depurated earthworms were ice-bath homogenized (Jingxin, F6/10, China) at high speed (30000 rpm for $30 \mathrm{~s}$ ) with phosphate buffer saline (PBS) then centrifuged (Eppendorf, Centrifuge $5810 \mathrm{R}$, Germany) at $3000 \mathrm{~g}\left(4^{\circ} \mathrm{C}\right)$ for $10 \mathrm{~min}$. The supernatant was collected and centrifuged at $20000 \mathrm{~g}\left(4^{\circ} \mathrm{C}\right)$ for 20 min after which the precipitate was resuspended in $1 \mathrm{~mL}$ PBS. To assess SOD, CAT, GST activity and MDA content, depurated earthworms were ice-bath homogenized at high speed with PBS and centrifuged at $10000 \mathrm{rpm}\left(4^{\circ} \mathrm{C}\right)$ for $10 \mathrm{~min}$. According to Bradford (1976), protein content of the above two samples was determined by Coomassie. To assess 8-OHdG content, depurated earthworms were ice-bath homogenized at high speed with PBS and centrifuged at $6500 \mathrm{rpm}$ $\left(4^{\circ} \mathrm{C}\right)$ for $15 \mathrm{~min}$.

An oxygen-sensitive fluorescent probe, 2', 7'- dichlorohydro fluorescein diacetate (DCFH-DA) was used as described by Zhang et al. (2013) to determine ROS content. DCFH-DA solution was added to the earthworm suspension to obtain a final concentration of $2 \mu \mathrm{M}$. Then the mixture was incubated for 30 min at $37^{\circ} \mathrm{C}$ in a water bath after which the fluorescence was monitored at an excitation wavelength of $488 \mathrm{~nm}$ and an emission wavelength of $522 \mathrm{~nm}$ using a fluorescent spectrophotometer (Shimadzu, RF5301PC). The ROS content was quantified as the fluorescence intensity and the unit was Fluorescence Intensity/mg pr.

SOD activity was determined by measuring the ability to inhibit the photochemical reduction of nitroblue tetrazolium chloride (NBT), as described by Song et al. (2009). The unit of SOD was U/mg pr (U: enzyme levels inhibited $50 \%$ NBT photochemical). The CAT activity was determined as described by Xu et al. (1997). One enzyme activity unit $(U)$ expresses the amount of enzyme required to decompose $50 \%$ hydrogen peroxide $\left(\mathrm{H}_{2} \mathrm{O}_{2}\right)$. GST activity was determined as described by Habig et al. (1974). The unit of CAT was $\mathrm{U} / \mathrm{mg}$ pr ( $\mathrm{U}$ : enzyme levels inhibited $50 \% \mathrm{H}_{2} \mathrm{O}_{2}$ ). GST activity was determined by measuring the amount of CDNB ( $\mathrm{nmol}$ ) reduced per min per $\mathrm{mg}$ pr. A kinetic approach was used to measure GST activity at $340 \mathrm{~nm}$ every $15 \mathrm{~s}$ from 0 to $180 \mathrm{~s}$ while MDA content was determined by thiobarbituric acid colorimetry (Han et al., 2014; Xiang and Wang, 1990). The unit of GST was $\mathrm{nmol} / \mathrm{min} / \mathrm{mg} \mathrm{pr}$ and the unit of MDA was nmol/mg pr. 
The 8-OHdG content was determined using an enzyme linked immunosorbent assay kit (Shanghai Hengyuan Biological Technology Co., Ltd, China) with content quantified by measuring absorbance at $450 \mathrm{~nm}$ using a microplate reader (MK3, Thermo Fisher, USA). The unit of 8-OHdG was ng/L.

\subsection{Statistical analyses}

The Statistical Package for Social Sciences (SPSS, V22.0) was used to analyze data and Origin (OriginPro, 2021, SR1) was used to plot figures. One-way analysis of variance (ANOVA) was used to analyze the least significance differences $(p<0.05)$ between the control treatment and each TCP exposure group.

Data from this study (TCP exposure) and our previous study (chlorpyrifos exposure) (Zhu et, al. 2020) were used to calculate the IBR index. The calculation of IBR was performed according to of Sanchez et al. (2013). See supplementary material for a detailed description of the calculation process.

\section{Results And Discussion}

\subsection{Effects of TCP on Eisenia fetida: biomarkers responses 3.1.1 Oxidative stress: ROS content and enzyme activities}

Reactive oxygen species (ROS) are highly reactive chemical species formed due to the electron acceptability of oxygen. Excessive ROS has a destructive effect and promotes oxidative stress (Li et al., 2019). Over a 56-day period, the variation in ROS level was assessed following exposure to TCP (Fig. 1). In all four soils, ROS in earthworms increased significantly when exposed to TCP. In the OECD artificial soil and black soil, a dose-response relationship that increasing ROS content occurred with increasing TCP concentration was observed whereby increasing ROS content was observed with increasing TCP concentration. In fluvo-aquic soil, a similar dose-response relationship that increasing ROS content occurred with increasing TCP concentration was observed except at day 56 where ROS content of 0.5 $\mathrm{mg} / \mathrm{kg}$ dose group decreased compared to the $0.1 \mathrm{mg} / \mathrm{kg}$ dose group. In red clay, no significant difference in ROS response was observed between the 0.01 and $0.1 \mathrm{mg} / \mathrm{kg}$ dose groups at day 7, 14, 42 and 56 as well as the 0.1 and $0.5 \mathrm{mg} / \mathrm{kg}$ dose groups on day 28 .

These results indicate that TCP exposure induces excessive ROS production in Eisenia fetida and, in most cases, a dose-response relationship that increasing ROS content occurred with increasing TCP concentration was observed. A similar result was observed in our previous study (Zhu et al., 2020) where exposure to TCP's parent compound, chlorpyrifos resulted in excessive ROS production in earthworms in the same four soils. Excessive ROS production in Eisenia fetida after exposure to TCP or chlorpyrifos indicates that these compounds cause oxidative stress to Eisenia fetida.

In order to mitigate oxidative stress caused by excessive ROS, Eisenia fetida may produce a battery of enzymes including SOD, CAT and GST. SOD and CAT, the first defense line of cellular protection (Wang et 
al., 2018; Singh et al., 2020), are produced by organisms to inactivate ROS preventing oxidative stress and subsequent damage. SOD can transform $\mathrm{O}_{2}{ }^{-}$into $\mathrm{H}_{2} \mathrm{O}_{2}$, which may then be detoxified by CAT (Liu et al., 2020b). These two enzymes (SOD and CAT) constitute the antioxidant enzyme system to jointly combat oxidative stress. GST contributes greatly to oxidation protection and xenobiotic metabolism, as it also detoxifies ROS in cells. (Zhu et al., 2011).

The detailed change in SOD, CAT and GST enzyme activities are illustrated in Fig. S1-S3. Unlike ROS content (Fig. 1), a dose-response was not observed for SOD, CAT, and GST following earthworm exposure to TCP. The SOD activity was significantly activated in all 4 soils in the early stage of exposure (7 days) but gradually decreased to a level similar to the unexposed control. However, CAT and GST activity was activated during most periods of TCP exposure. Assessment of these biomarkers individually do not provide a clear indication of exposure effect. As a consequence, to clearly evaluate Eisenia fetida oxidative stress in different soils caused by TCP exposure, the IBR index was calculated using SOD, CAT and GST (IBR index of SCG) activity to describe an integrated biomarker response. The IBR index may indicate pollutant toxicity and be used to assess environmental pollution risk (Wang et al., 2011; Shao et al., 2019). The normalized calculated IBR index of SCG is illustrated in Fig. 2.

The variation in Eisenia fetida enzyme activities (SCG) shows the early oxidative stress caused by TCP. The oxidative damages suffered by earthworms in 4 soils are different. During the experimental period, the IBR index of SCG in red clay was higer than that in the other three soils. On day 7 and 14, the IBR index of SCG in black soil was little higher than that in fluvo-aquic soil and much higher than that in artificial soil. On day 28,42 and 56 , the IBR index of SCG in fluvo-aquic soil was much higher than that in artificial and black soil.

\subsubsection{Lipid peroxidation: MDA content}

Excessive ROS can cause lipid peroxidation (LPO), which damages cell membranes and causes cell damage. MDA content could reflect the degree of LPO (Box and Maccubbin, 1997). Fig. 3 illustrates the changes in Eisenia fetida MDA content influenced by TCP in soils. For all soil and timeframe, MDA content was significatnly higher in earthworms exposed to 0.1 and $0.5 \mathrm{mg} \mathrm{TCP} / \mathrm{kg}$ compared to unexposed controls. While elevated MDA content was also observed in the $0.01 \mathrm{mg} / \mathrm{kg}$ exposure group, at some time points, there was no significant diference in MDA concentration between exposed earthworms and unexposed controls. As detailed by Zhu et, al. (2020), chlorpyrifos exposure significantly increased MDA content in Eisenia fetida over a 4 week exposure. Li et al. (2019) demonstrated that another organophosphorus insecticide tolclofos-methyl could also significantly increased MDA content in Eisenia fetida. MDA content could reflect the degree of LPO. Uniformly, MDA content in Eisenia fetida was significantly increased after exposure to TCP and the increase was more obvious in the later stage of the experiment. This indicates that TCP exposure caused LPO to Eisenia fetida.

\subsubsection{DNA oxidative damage: 8-OHdG content}


The product generated when ROS attacking DNA (Guo et al., 2014), 8-hydroxy-2-deoxyguanosine (8$\mathrm{OHdG}$ ), is an indicator of the degree of oxidative and DNA damage (Zhang et al., 2014). Fig. 4 illustrates changes in earthworm 8-OHdG content in different soils after exposure to TCP.

In artificial soil, 8-OHdG content of each concentration group was significantly higher than that of control groups. However, a significant difference between the 0.1 and $0.5 \mathrm{mg} / \mathrm{kg}$ exposure group was not observed on day 42. Furthermore, on day $28,8-\mathrm{OHdG}$ content in the $0.1 \mathrm{mg} / \mathrm{kg}$ exposure was significantly lower than that of 0.01 and $0.5 \mathrm{mg} / \mathrm{kg}$ exposure groups. In natural soils, the $8-\mathrm{OHdG}$ in TCP concentration groups were significantly higher than that of $0 \mathrm{mg} / \mathrm{kg}$. A dose-response relationship that increasing 8OHdG content occurred with increasing TCP concentration was observed.

The increase in 8-OHdG content indicates that TCP induced DNA damage to Eisenia fetida. As we previously determined (Zhu et, al., 2020), chlorpyrifos treatments also significantly increased the earthworm's 8-OHdG content. Zhang et al. (2014) also demonstrated that Dechlorane Plus could induce an increase of earthworm's 8-OHdG content. Besides, 1-methyl-3-(tetrahydro-3-furylmethyl) urea and 1methyl-3-(tetrahydro-3-furylmethyl) guanidium dihydrogen, which are two main metabolites of the insecticide dinotefuran, were stated that induced DNA damage in Eisenia fetida cells (Liu et al., 2018). Based on the response of 8-OHdG content to TCP exposure, TCP induced excessive ROS production in earthworms, and ROS attacks DNA to cause DNA oxidative damage to Eisenia fetida in all four soils.

Results highlight that TCP exposure induces adverse effects on earthworms as TCP can induce excessive ROS, alter enzyme activity, induce LPO as well as DNA damage. In addition, the effects on Eisenia fetida of TCP in red clay was higher than that in the other three soils, followed by fluvo-aquic soil and black soil, the lowest was artificial soil. Organic matter, $\mathrm{pH}$, cation exchange capacity and clay content could interact with chemical substances (Stepnowski et al., 2007; Gebremariam et al., 2012). The IBR index of SCG indicates that oxidative stress caused by TCP in red clay and fluvo-aquic soil was higher than that in artificial and black soil. This may be due to lower organic carbon content in red clay and fluvo-aquic soil compared to artificial soil and black soil. Zhu et al. (2020) demonstrated that chlorpyrifos was more toxic to Eisenia fetida in red clay with high clay content (71.3\%). Xu et al. (2021) and Zhang et al. (2020) stated that azoxystrobin and fluoxastrobin had more lasting adverse effects on earthworms in soils with low organic matter content and low $\mathrm{pH}$. These results are consistent with that in the present study, TCP also has a greater influence on SCG in red clay than in the other three soils. In general, the higher toxicity of TCP in red clay than the other three soils may be due to the fact that red clay has lower organic matter and $\mathrm{pH}$, and higher clay content $(71.3 \%)$ than the other three soils. Based on the effects of TCP on SCG activity in earthworms in different soils as shown in Fig. 2, we believe that artificial soil toxic experiment may not correctly evaluate the toxicity of TCP in natural soil including fluvo-aquic soil and red clay.

TCP has a similar effect that increase ROS content, affect SCG activity, and cause lipid peroxidation and DNA oxidative damage to earthworms compared to the parent chemical chlorpyrifos. However, the toxicity of TCP and chlorpyrifos to earthworms may further be elucidated by calculating the IBR index.

\subsection{Toxicity comparison of TCP and chlorpyrifos: IBR index}


In the present study, IBR index of each exposure group was the sum of six biomarker responses (ROS, SOD, CAT, GST, MDA, 8-OHdG). Fig. 5A illustrates the IBR index of chlorpyrifos (Zhu et, al., 2020) and TCP when Eisenia fetida was exposed to $0.1 \mathrm{mg} / \mathrm{kg}$ for 28 days and 56 days in different soils. Fig. 5B illustrates the change in each biomarker over this time frame. Data on the effects of chlorpyrifos on earthworms (ROS, SOD, CAT, GST, MDA, 8-OHdG) were obtained from our previous study (Zhu et al., 2020).

As shown in Fig. 5A, on day 28, the IBR index for TCP was significantly higher that chlorpyrifos, more so for fluvo-aquic soil and black soil. In contrast, at day 56 higher IBR indices were observed for chlorpyrifos compared to TCP particularly for artificial soil and red clay. It is also worth mentioning that TCP was less toxic on day 56 than on day 28 , but chlorpyrifos was more toxic. Fig. $5 B$ illustrates the degree of contribution of biomarkers to IBR index. In artificial soil, 8-OHdG content contributed the most to the IBR index of chlorpyrifos and TCP to Eisenia fetida. In fluvo-aquic soil, SOD activity contributed the most to the IBR index of chlorpyrifos while 8-OHdG content contributed the most to the IBR index of TCP to Eisenia fetida. In black soil, 8-OHdG content contributed the most to the IBR index of chlorpyrifos while MDA content contributed the most to the IBR index of TCP to Eisenia fetida. In red clay, MDA content contributed the most to the IBR index to chlorpyrifos while CAT activity contributed the most to the IBR index of TCP to Eisenia fetida. In general, the production of lipid peroxidation MDA content and the production of DNA damage 8-OHdG content were most sensitive to TCP contamination.

There have also been several reports comparing the toxicity of chlorpyrifos with its metabolite TCP. For aquatic organisms, TCP was found to be more toxic than chlorpyrifos to Daphnia carinata survival in cladoceran water ( $\mathrm{LC}_{50}$ values were 0.20 and $0.24 \mu \mathrm{g} / \mathrm{L}$, respectively) (Cáceres et al., 2007). EcheverriJaramillo et al. (2020) found that TCP was more toxic than chlorpyrifos to Aliivibrio fischeri $\left(\mathrm{IC}_{50}\right.$ values were 0.98 and $2.9 \mathrm{mg} / \mathrm{L}$, respectively) and Pseudokirchneriella subcapitata $\left(\mathrm{IC}_{50}\right.$ values were 0.29 and $1.11 \mathrm{mg} / \mathrm{L}$, respectively). This suggests that chlorpyrifos itself may be less toxic than TCP, but once degraded and converted to TCP or other transformation products, it becomes more toxic. Kharabsheh et al. (2017) demonstrated that the bacteria Pseudomonas aeruginosa metabolized chlorpyrifos to TCP increasing the mortality of adult zebrafish (Danio rerio). Besides, Li et al. (2020) demonstrated that TCP had a key role in chlorpyrifos-induced decrease in testosterone synthesis of mice. In combination with the present study, for terrestrial organisms especially earthworms (Eisenia fetida), TCP was more toxic than its parent chemical chlorpyrifos after 28 days exposure but less toxic after 56 days exposure.

\section{Conclusions}

In the present study, the oxidative stress and damage of TCP to Eisenia fetida was determined in artificial soil prepared according to the OECD and three natural soils (fluvo-aquic soil, black soil and red clay) by monitoring change in biomarker responses (ROS, SOD, CAT, GST, MDA, 8-OHdG). The IBR index was calculated to compare the response to TCP with chlorpyrifos to Eisenia fetida in different soils. According to the results, the primary conclusions were as follows: 
(1) TCP $(0.01-0.5 \mathrm{mg} / \mathrm{kg})$ caused oxidative stress and DNA oxidative damage to Eisenia fetida and artificial soil toxicity experiment may underestimate the TCP oxidative stress to Eisenia fetida in natural soil.

(2) As the metabolite compound of chlorpyrifos, TCP was less toxic than chlorpyrifos after over a 56-days exposure at the same dose $(0.1 \mathrm{mg} / \mathrm{kg})$.

Based on previous studies, we speculate that this is due to chlorpyrifos metabolism to TCP and other metabolites after 56 days. Thus, an approach to monitor the concentration changes in chlorpyrifos and TCP should be established in future studies to demonstrating this. Despite the deficiencies of this study, the above information is of great significance for assessing the risk of chlorpyrifos and its metabolite TCP pollution in soil ecosystems.

\section{Declarations}

\section{Acknowledgement}

Many thanks to Prof. Albert Juhasz from the University of South Australia made a language editing for our manuscript.

\section{Ethics approval and consent to participate}

Not applicable

\section{Consent for publication}

Not applicable

\section{Availability of data and materials}

The authors confirm that the data supporting the findings of this study are available within the article and supplement materials.

\section{Competing interests}

The authors declare that they have no competing interests

\section{Funding}

The present study was supported by the National Natural Science Foundation of China [grant numbers 42077042 and 41907357].

\section{Authors' contributions}


Kaixuan Hou: Conceptualization, Formal analysis, Investigation, Writing - original draft, review and editing.

Yue Yang: Validation, Formal analysis, Writing - review \& editing; Lei Zhu: Conceptualization, Investigation.

Ruolin Wu: Validation, Investigation; Zhongkun Du: Writing - review \& editing; Bing Li: Writing - review \& editing; Lusheng Zhu: Conceptualization, Methodology, Investigation, Validation, Supervision, Funding acquisition, Project administration, Writing - review \& editing; Shujuan Sun: Funding acquisition, Supervision, Project administration.

\section{References}

Ali, D., Nagpure, N.S., Kumar, S., Kumar, R., Kushwaha, B. and Lakra, W.S., 2009. Assessment of genotoxic and mutagenic effects of chlorpyrifos in freshwater fish Channa punctatus (Bloch) using micronucleus assay and alkaline single-cell gel electrophoresis. Food and Chemical Toxicology 47(3), 650656. https://doi.org/10.1016/j.fct.2008.12.021

Bassey, Y.I., Effiong E.B., Archibong, U.D., Ita, W.I., 2015. Germination and Root Nodule Formation of Soybean (Glycine max (L.) Merr.) in Ridomil and Chlorpyriphos Treated Soil. American Journal of Environmental Protection 4(1), 17-22. https://doi.org/10.11648/j.ajep.20150401.12

Bempelou, E.D., Vontas, J.G., Liapis, K.S., Ziogas, V.N., 2018. Biodegradation of chlorpyrifos and 3,5,6trichloro-2-pyridinol by the epiphytic yeasts Rhodotorula glutinis and Rhodotorula rubra. Ecotoxicology 27(10), 1368-1378. https://doi.org/10.1007/s10646-018-1992-7

Blakemore, R.J., Hochkirch, A., 2017. Restore earthworms to rebuild topsoil. Nature 545, 30. https://doi.org/10.1038/545030b

Bonifacio, A.F., Ballesteros, M.L., Bonansea, R.I., Filippi, I., Ame, M.V., Hued, A.C., 2017. Environmental relevant concentrations of a chlorpyrifos commercial formulation affect two neotropical fish species, Cheirodon interruptus and Cnesterodon decemmaculatus. Chemosphere 188, 486-493. https://doi.org/10.1016/j.chemosphere.2017.08.156

Box, H.C., Maccubbin, A.E., 1997. Lipid peroxidation and DNA damage. Nutrition 3, 920-921. https://doi.org/10.1016/S0899-9007(97)00260-8

Bradford, M.M., 1976. A rapid sensitivemethod for the quantification of microgram quantities of protein utilizing the principle of protein-dye binding. Analytical Biochemistry 72, 248-254. https://doi.org/10.1016/0003-2697(76)90527-3

Cáceres, T., He, W.X., Naidu, R., Megharaj, M., 2007. Toxicity of chlorpyrifos and TCP alone and in combination to Daphnia carinata: the influence of microbial degradation in natural water. Water Research 
41(19), 4497-4503. https://doi.org/10.1016/j.watres.2007.06.025

Costa, E., Gambardella, C., Piazza, V., Greco, G., Lavorano, S., Beltrandi, M., Bongiovanni, E., Gnone, G., Faimali, M., Garaventa, F., 2015. Effect of neurotoxic compounds on ephyrae of Aurelia aurita jellyfish. Hydrobiologia 759(1), 75-84. https://doi.org/10.1007/s10750-015-2284-3

Deng, Y.F., Zhang, Y., Lu, Y.F., Zhao, Y.P., Ren, H.Q., 2016. Hepatotoxicity and nephrotoxicity induced by the chlorpyrifos and chlorpyrifos-methyl metabolite, 3,5,6-trichloro-2-pyridinol, in orally exposed mice. Science of The Total Environment 544, 507-514. https://doi.org/10.1016/j.scitotenv.2015.11.162

Dutta, M., Sardar, D., Pal, R. and Kole, R.K., 2010. Effect of chlorpyrifos on microbial biomass and activities in tropical clay loam soil. Environmental Monitoring and Assessment 160(1-4), 385-391. https://doi.org/10.1007/s10661-008-0702-y

Echeverri-Jaramillo, G., Jaramillo-Colorado, B., Sabater-Marco, C. and Castillo-Lopez, M. Á., 2020. Acute toxicity of chlorpyrifos and its metabolite 3,5,6-trichloro-2-pyridinol alone and in combination using a battery of bioassays. Environmental Science and Pollution Research 27(26), 32770-32778. https://doi.org/10.1007/s11356-020-09392-x

Garcia-Gomez, C., Babin, M., Garcia, S., Almendros, P., Perez, R.A., Fernandez, M.D., 2019. Joint effects of zinc oxide nanoparticles and chlorpyrifos on the reproduction and cellular stress responses of the earthworm Eisenia andrei. Science of The Total Environment 688, 199-

207. https://doi.org/10.1016/j.scitotenv.2019.06.083

Gebremariam, S.Y., Beutel, M.W., Flury, M., Harsh, J.B., Yonge, D.R., 2012. Nonsingular adsorption/desorption of chlorpyrifos in soils and sediments: experimental results and modeling. Environmental Science \& Technology 46(2), 869-875. https://doi.org/10.1021/es203341b

Guo, Y., Weck, J., Sundaram, R., Goldstone, A.E., Louis, G.B., Kannan, K., 2014. Urinary concentrations of phthalates in couples planning pregnancy and its association with 8-hydroxy-2'-deoxyguanosine, a biomarker of oxidative stress: Iongitudinal investigation of fertility and the environment study. Environmental Science \& Technology 48(16), 9804-9811. https://doi.org/10.1021/es5024898

Habig, W.H., Pabst, M.J. and Jakoby, W.B. 1974. Glutathione S-Transferases: THE FIRST ENZYMATIC STEP IN MERCAPTURIC ACID FORMATION. Journal of Biological Chemistry 249, 7130-7139. https://doi.org/10.1016/S0021-9258(19)42083-8

Han, Y., Zhu, L., Wang, J., Wang, J., Xie, H. and Zhang, S. 2014. Integrated assessment of oxidative stress and DNA damage in earthworms (Eisenia fetida) exposed to azoxystrobin. Ecotoxicology and Environmental Safety. 107, 214-219. https://doi.org/10.1016/j.ecoenv.2014.06.006

John, E.M., Shaike, J.M., 2015. Chlorpyrifos: pollution and remediation. Environmental Chemistry Letters 13(3), 269-291. https://doi.org/10.1007/s10311-015-0513-7

Page $11 / 20$ 
Kharabsheh, H.A., Han, S.B., Allen, S., Chao, S.L., 2017. Metabolism of chlorpyrifos by Pseudomonas aeruginosa increases toxicity in adult zebrafish (Danio rerio). International Biodeterioration \& Biodegradation 121, 114-121. https://doi.org/10.1016/j.ibiod.2017.03.024

Li, J.W., Fang, B., Ren, F.Z., Xing, H.Z., Zhao, G.P., Yin, X.F., Pang, G.F., Li, Y.X., 2020. TCP structure intensified the chlorpyrifos-induced decrease in testosterone synthesis via LH-LHR-PKA-CREB-Star pathway. Science of The Total Environment 726,

138496. https://doi.org/10.1016/j.scitotenv.2020.138496

Li, M., Wang, S., Lang, Z., Xu, G.H., Yu, Y., 2019. Combination of chemical and toxicological methods to assess bioavailability of Tolclofos-methyl by earthworms. Chemosphere 233, 183189. https://doi.org/10.1016/j.chemosphere.2019.05.215

Liu, T., Liu, Y.L., Fang, K., Zhang, X.L., Wang, X.G., 2020a. Transcriptome, bioaccumulation and toxicity analyses of earthworms (Eisenia fetida) affected by trifloxystrobin and trifloxystrobin acid. Environmental Pollution 265, 115100. https://doi.org/10.1016/j.envpol.2020.115100

Liu, T., Zhang, X.L., Wang, X.G., Chen, D., Li, Y.Q., Wang, F.L., 2018. Comparative toxicity and bioaccumulation of two dinotefuran metabolites, UF and DN, in earthworms (Eisenia fetida). Environmental Pollution 234, 988-996. https://doi.org/10.1016/j.envpol.2017.12.007

Liu, Y.M., Li, L., Zheng, L., Fu, P., Wang, Y., Nguyen, H., Shen, X.S., Sui, Y.M., 2020b. Antioxidant responses of triangle sail mussel Hyriopsis cumingii exposed to harmful algae Microcystis aeruginosa and high $\mathrm{pH}$. Chemosphere 243, 125241. https:// doi.org/10.1016/j.chemosphere.2019.125241

OECD, 2016. Test No. 222: Earthworm Reproduction Test (Eisenia fetida/Eisenia andrei), OECD Guidelines for the Testing of Chemicals, Section 2, OECD Publishing, Paris.

Ojha, A., Yaduvanshi, S.K., Pant, S.C., Lomash, V., Srivastava, N., 2013. Evaluation of DNA damage and cytotoxicity induced by three commonly used organophosphate pesticides individually and in mixture, in rat tissues. Environmental Toxicology 28(10), 543-552. https://doi.org/10.1002/tox.20748

Orts, A., Cabrera, S., Gómez, I., Parrado, J., Rodriguez-Morgado, B., Tejada, M., 2017. Use of okara in the bioremediation of chlorpyrifos in soil: Effects on soil biochemical properties. Applied Soil Ecology 121, 172-176. https://doi.org/10.1016/j.apsoil.2017.09.042

Rafique, N., Tariq, S.R. and Ahmed, D. 2016. Monitoring and distribution patterns of pesticide residues in soil from cotton/wheat fields of Pakistan. Environ. Monit. Assess. 188, 695.

https://doi.org/10.1007/s10661-016-5668-6

Samanta, P., Im, H., Na, J., Jung, J., 2018. Ecological risk assessment of a contaminated stream using multi-level integrated biomarker response in Carassius auratus. Environmental Pollution 233, 429438. https://doi.org/10.1016/j.envpol.2017.10.061 
Sanchez-Hernandez, J.C., Ríos, J.M., Attademo, A.M., Malcevschi, A., Andrade Cares, X., 2019. Assessing biochar impact on earthworms: Implications for soil quality promotion. Journal of Hazardous Materials 366, 582-591. https://doi.org/10.1016/j.jhazmat.2018.12.032

Sanchez, W., Burgeot, T., Porcher, J.M., 2013. A novel "Integrated Biomarker Response" calculation based on reference deviation concept. Environmental Science and Pollution Research 20(5), 27212725. https://doi.org/10.1007/s11356-012-1359-1

Sandal, S., Yilmaz, B., 2011. Genotoxic effects of chlorpyrifos, cypermethrin, endosulfan and 2,4-D on human peripheral lymphocytes cultured from smokers and nonsmokers. Environmental Toxicology 26(5), 433-442. https://doi.org/10.1002/tox.20569

Shao, Y.T., Hou, K.X., Du, Z.K., Li, B., Wang, J., Juhasz, A., Wang, J.H., Zhu, L.S., 2019. Evaluation of the toxicity of 1-butyl-3-methyl imidazolium tetrafluoroborate using earthworms (Eisenia fetida) in two soils. Science of The Total Environment 686, 946-958. https://doi.org/10.1016/j.scitotenv.2019.06.010

Singh, S., Tiwari, R.K. and Pandey, R.S. 2020. An insight into the impact of triazophos and deltamethrin pesticides as individual and in combination on oxidative stress and histopathological alterations in Eudrilus eugeniae. Chemistry and Ecology 36, 155-173. https://10.1080/02757540.2019.1699536

Song, Y., Zhu, L.S., Wang, J., Wang, J.H., Liu, W. and Xie, H. 2009. DNA damage and effects on antioxidative enzymes in earthworm (Eisenia foetida) induced by atrazine. Soil Biology and Biochemistry 41, 905-909. https://doi.org/10.1016/j.soilbio.2008.09.009

Stepnowski, P., Wojciech M., Nichthauser, J., 2007. Adsorption of alkyl imidazolium and alkyl pyridinium ionic liquids onto natural soils. Environmental Science \& Technology 41 (2), 511 516. https://doi.org/10.1021/es062014w

Suvarchala, G., Philip, G.H., 2016. Toxicity of 3,5,6-trichloro-2-pyridinol tested at multiple stages of zebrafish (Danio rerio) development. Environmental Science and Pollution Research 23(15), 1551515523. https://doi.org/10.1007/s11356-016-6684-3

Tiwari, R.K., Singh, S. and Pandey, R.S. 2019. Assessment of acute toxicity and biochemical responses to chlorpyrifos, cypermethrin and their combination exposed earthworm, Eudrilus eugeniae. Toxicology Reports 6, 288-297. https://doi.org/10.1016/j.toxrep.2019.03.007

Wang, C., Lu, G.H., Wang, P.F., Wu, H., Qi, P.D., Liang, Y., 2011. Assessment of environmental pollution of Taihu Lake by combining active biomonitoring and integrated biomarker response. Environmental Science \& Technology 45(8), 3746-3752. https://doi.org/10.1021/es1037047

Wang, G.Y., Wang, J., Zhu, L.S., Wang, J.H., Li, H.Z., Zhang, Y.Z., Liu, W.J., Gao, J.P., 2018. Oxidative Damage and Genetic Toxicity Induced by DBP in Earthworms (Eisenia fetida). Archives of Environmental Contamination and Toxicology 74(4), 527-538. https://doi.org/10.1007/s00244-017-0451-4 
Wang, J., Wang, J.H., Zhu, L.S., Xie, H., Shao, B., Hou, X.X., 2014. The enzyme toxicity and genotoxicity of chlorpyrifos and its toxic metabolite TCP to zebrafish Danio rerio. Ecotoxicology 23(10), 1858-

1869. https://doi.org/10.1007/s10646-014-1321-8

Wang, J.H., Zhu, L.S., Liu, W., Wang, J., Xie, H., 2012. Biochemical responses of earthworm (Eisenia foetida) to the pesticides chlorpyrifos and fenvalerate. Toxicology Mechanisms and Methods 22(3), 236241. https://doi.org/10.3109/15376516.2011.640718

Wang, S.H., Zhang, C., Lv, Z.W., Huang, H.M., Cao, X.T., Song, Z.F., Shao, M.Z., 2019. Degradation of 3,5,6trichloro-2-pyridinol by a microbial consortium in dryland soil with anaerobic incubation. Biodegradation 30(2-3), 161-171. https://doi.org/10.1007/s10532-019-09873-y

Xiang, R. and Wang, D.N. 1990. The improvement of lipid peroxidation thiobarbituric acid spectrophotometry. Progress in Biochemistry and Biophysics 17, 241-242.

Xu, J.B., Yuan, X.F., Lang, P.Z., 1997. The determination of enzymic activity and its inhibition on catalase by ultraviolet spectrophotometry. Environmental Chemistry. 16, 73-76.

Xu Y.Q., Li B., Hou K.X., Du Z.K., Allen C.S., Zhu L.S., Li W.X., Zhu L., Wang J.H. Wang J. 2021. Ecotoxicity evaluation of azoxystrobin on Eisenia fetida in different soils. Environmental Research 194, 110705. https://doi.org/10.1016/j.envres.2020.110705

Yu, X.F, Zhu, H., Yan, B.X., Xu, Y.Y., Banuelos, G., Shutes, B., Wen, H.Y., Cheng, R., 2019. Removal of chlorpyrifos and its hydrolytic metabolite 3,5,6-trichloro-2-pyridinol in constructed wetland mesocosms under soda saline-alkaline conditions: Effectiveness and influencing factors. Journal of Hazardous Materials 373, 67-74. https://doi.org/10.1016/j.jhazmat.2019.03.052

Žabar, R., Sarakha, M., Lebedev, A.T., Polyakova, O.V., Trebse, P., 2016. Photochemical fate and photocatalysis of 3,5,6-trichloro-2-pyridinol, degradation product of chlorpyrifos. Chemosphere 144, 615620. https://doi.org/10.1016/j.chemosphere.2015.09.030

Zhang, C., Wang, S.H., Lv, Z.W., Zhang, Y., Cao, X.T., Song, Z.F., Shao, M.Z., 2019. $\mathrm{NanoFe}_{3} \mathrm{O}_{4}$ accelerates anoxic biodegradation of 3, 5, 6-trichloro-2-pyridinol. Chemosphere 235, 185-

193. https://doi.org/10.1016/j.chemosphere.2019.06.114

Zhang, C., Zhou, T., Du, Z., Juhasz, A., Zhu, L., Wang, J., Wang, J. and Li, B. 2020. Applying fungicide on earthworms: Biochemical effects of Eisenia fetida exposed to fluoxastrobin in three natural soils. Environmental Pollution. 258, 113666. https://doi.org/10.1016/j.envpol.2019.113666

Zhang, C., Zhu, L.S., Wang, J., Wang, J.H., Du, Z., Li, B., Zhou, T.T., Cheng, C., Wang, Z.B., 2018. Evaluating subchronic toxicity of fluoxastrobin using earthworms (Eisenia fetida). Science of The Total Environment 642, 567-573. https://doi.org/10.1016/j.scitotenv.2018.06.091 
Zhang, L.J., Ji, F.N., Li, M., Cui, Y.B., Wu, B., 2014. Short-term effects of Dechlorane Plus on the earthworm Eisenia fetida determined by a systems biology approach. Journal of Hazardous Materials 273, 239246. https://doi.org/10.1016/j.jhazmat.2014.03.018

Zhang, Q., Zhu, L., Wang, J., Xie, H., Wang, J., Han, Y. and Yang, J. 2013. Oxidative stress and lipid peroxidation in the earthworm Eisenia fetida induced by low doses of fomesafen. Environmental Science and Pollution Research 20, 201-208. https://doi.org/10.1007/s11356-012-0962-5

Zhu, L.S., Dong, X.L., Xie, H., Wang, J., Wang, J.H., Su, J., Yu, C.W., 2011. DNA damage and effects on glutathione-S-transferase activity induced by atrazine exposure in zebrafish (Danio rerio). Environmental Toxicology 26(5), 480-488. https://doi.org/10.1002/tox.20575

Zhu, L., Li, B., Wu, R.L., Li, W.X., Wang, J., Wang, J.H., Du, Z.K., Juhasz, A., Zhu, L.S., 2020. Acute toxicity, oxidative stress and DNA damage of chlorpyrifos to earthworms (Eisenia fetida): The difference between artificial and natural soils. Chemosphere 255, 126982.

https://doi.org/10.1016/j.chemosphere.2020.126982

\section{Figures}

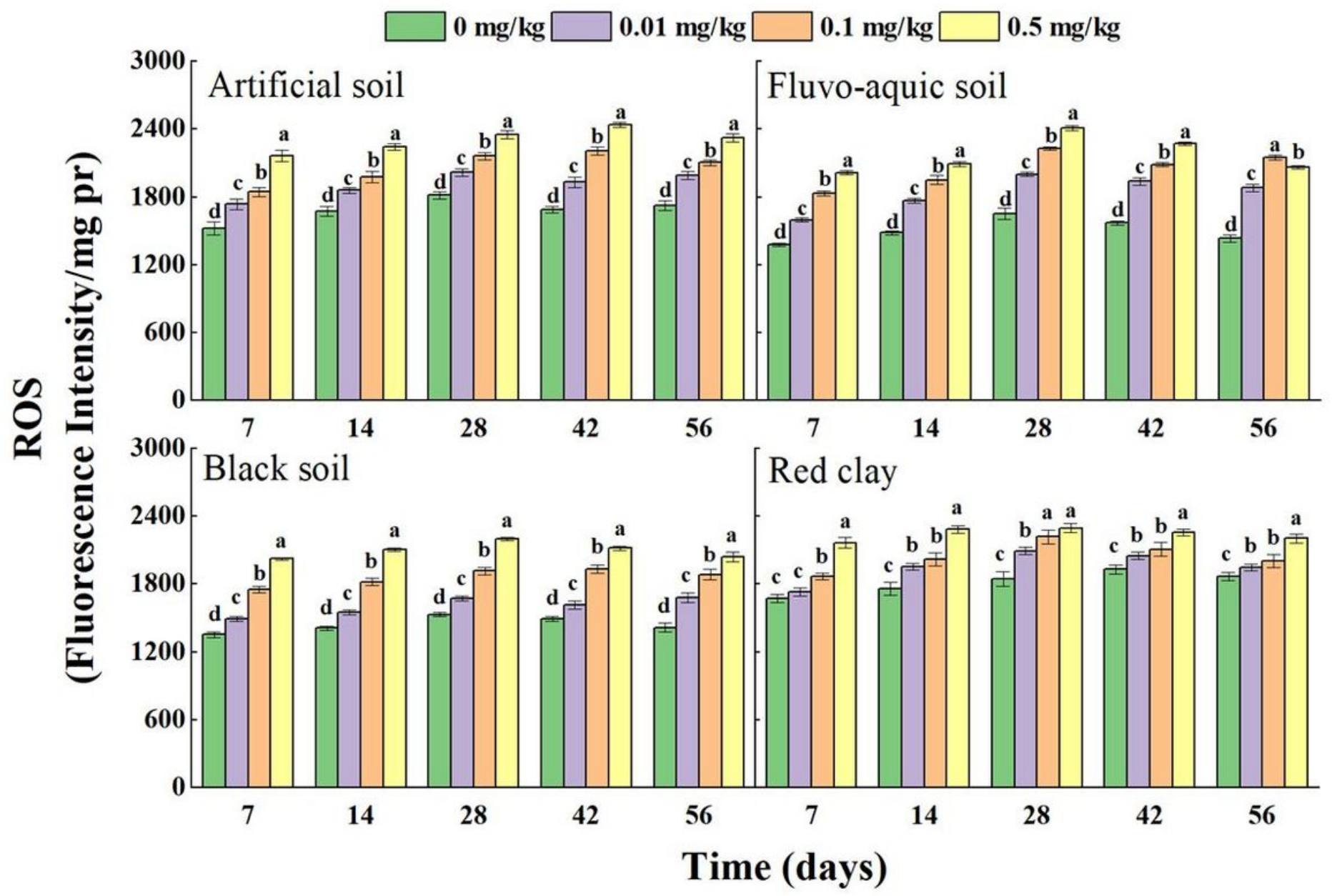


Figure 1

TCP concentration effect on earthworm's ROS content in different soils. The columns represent means \pm standard error (SE). Different letters above columns represents a significant difference between groups at the same exposure time point $(p<0.05)$.

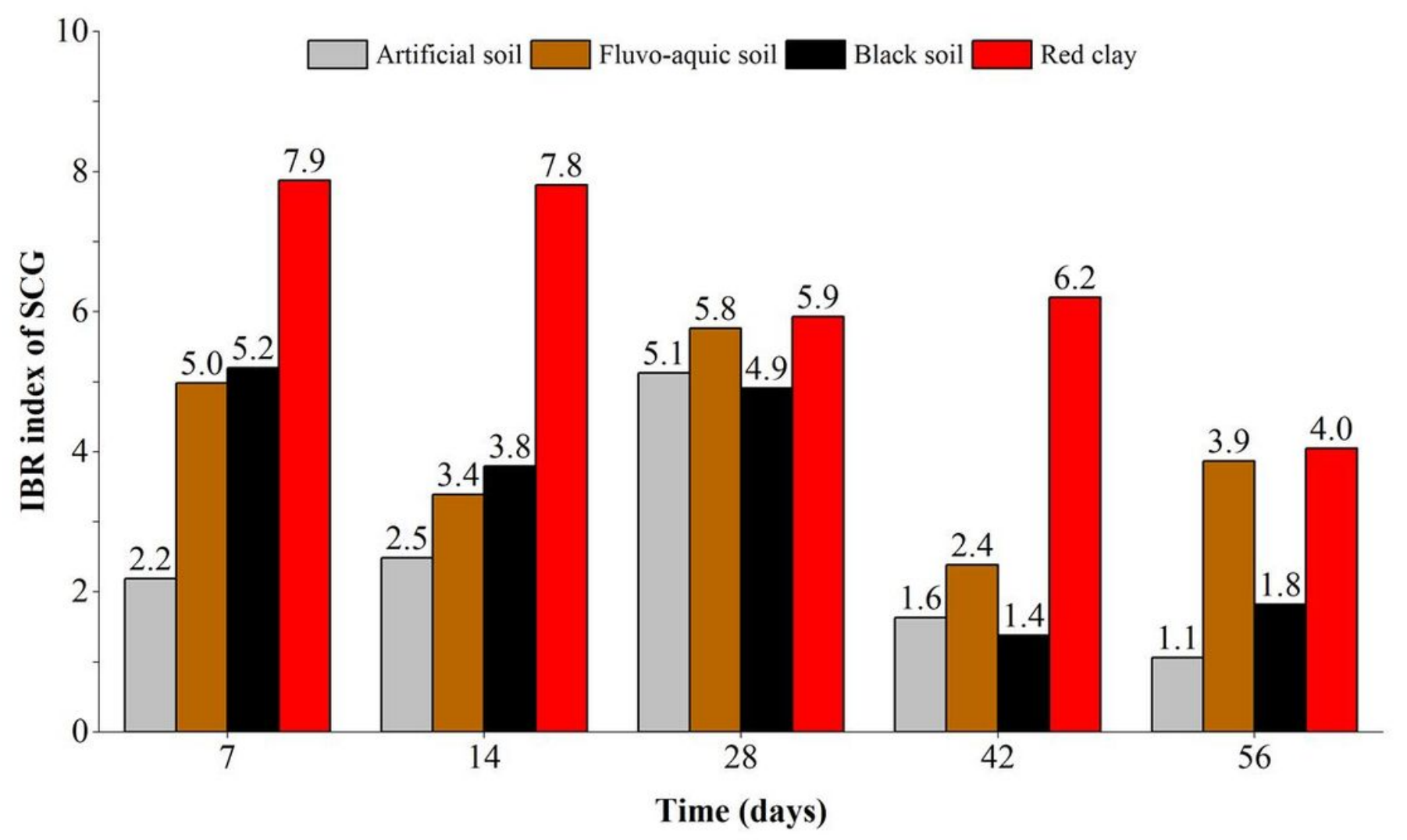

Figure 2

Integrated biomarker response (IBR) index calculated using SOD, CAT and GST (IBR index of SCG) assay outcomes following expousure to $0.1 \mathrm{mg} \mathrm{TCP} / \mathrm{kg}$. Columns represent the IBR index as calcualted in the Supplementary Materials with larger IBR indeces representing greater effect on SCG. 


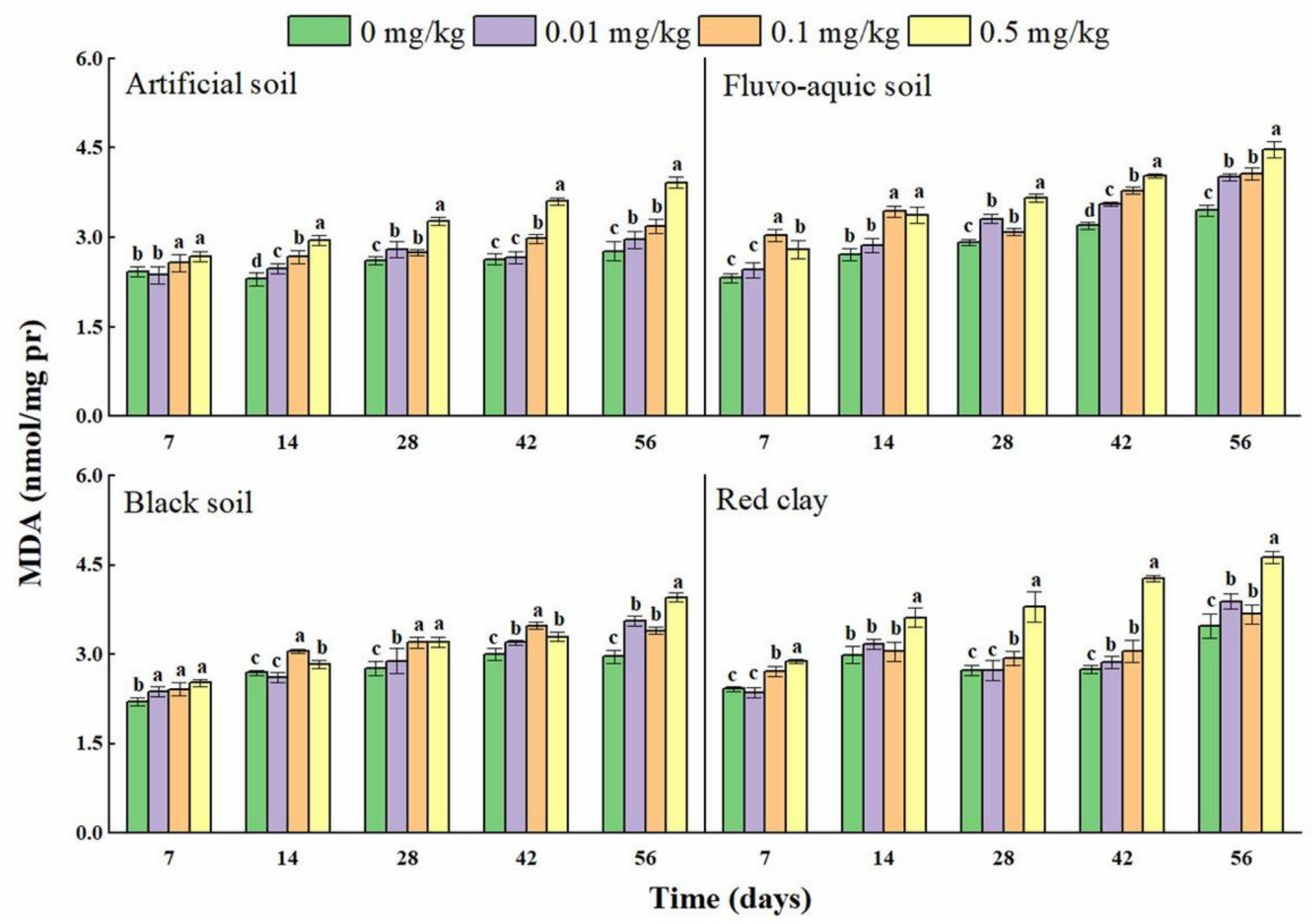

Figure 3

Effect of TCP concentration on MDA content in Eisenia fetida in different soils. The columns represented means \pm standard error (SE). Different letters above columns represent a significant difference between concentrations in the same exposure time period $(p<0.05)$. 


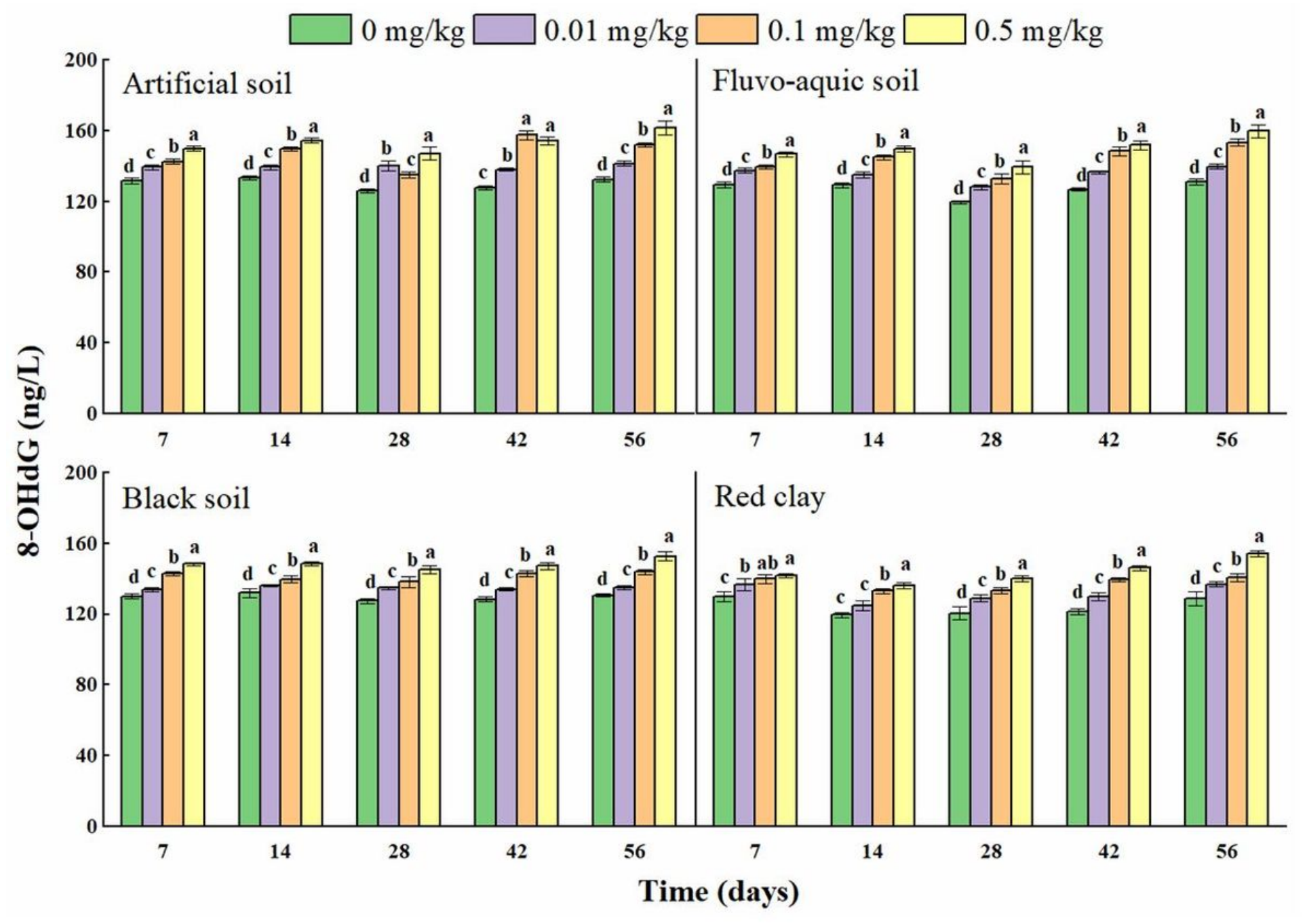

Figure 4

Effect of TCP on 8-OHdG concentration in earthworms. The columns represented means \pm standard error (SE). Different letters above columns represents a significant difference between concentrations in the same exposure time period $(p<0.05)$ 

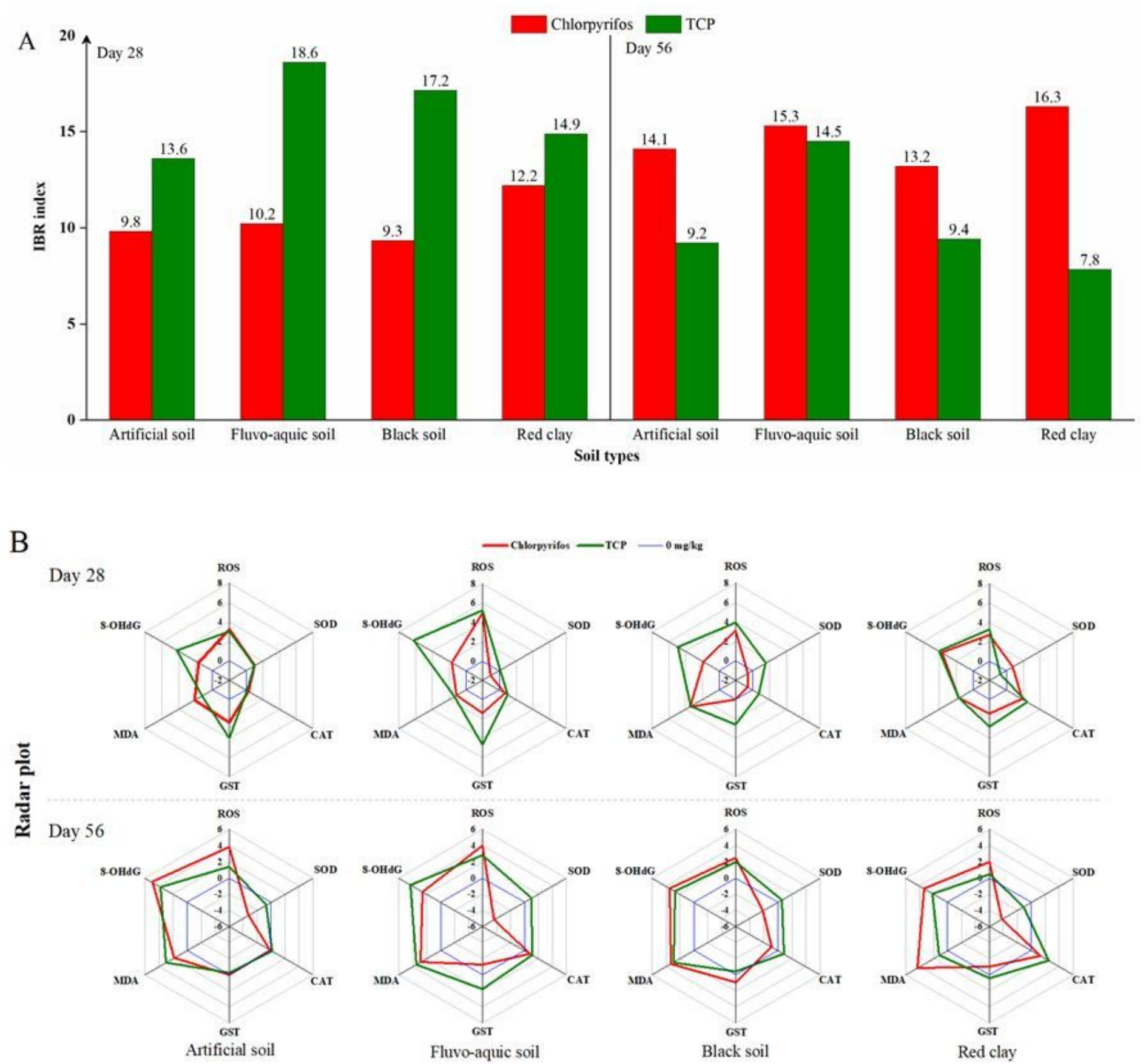

Figure 5

IBR index (A) and radar plot (B) of Eisenia fetida biomarker response to $0.1 \mathrm{mg} / \mathrm{kg}$ chlorpyrifos (Zhu et, al. 2020) or TCP exposure after 28 and 56 days. The larger the IBR index, the greater effect on biomarkers is. The blue line in the radar plot indicates the solvent control group $(0 \mathrm{mg} / \mathrm{kg})$ values for Eisenia fetida. Data points outside the blue line indicates over expression while values inside the blue line indicates under expression.

\section{Supplementary Files}


This is a list of supplementary files associated with this preprint. Click to download.

- Supplementarymaterial.doc 